\title{
Structural Modification of Cellulosic Fabric via Esterification Using Jatropha curcas Seed Oil
}

\author{
F. I. Omizegba ${ }^{1 *}$, K. A. Bello ${ }^{2}$, J. O. Abayeh ${ }^{3}$, H. M. Adamu ${ }^{1}$, \\ D. E. A. Boryo ${ }^{1}$ and S. A. Osemeahon ${ }^{4}$ \\ ${ }^{1}$ Department of Chemistry, Abubakar Tafawa Balewa University, Bauchi, Nigeria. \\ ${ }^{2}$ Department of Textile Technology, Ahmadu Bello University, Zaria, Nigeria. \\ ${ }^{3}$ Department of Pure and Industrial Chemistry, University of Port Harcourt, Nigeria. \\ ${ }^{4}$ Department of Chemistry, Modibbo Adama University of Technology, Yola, Nigeria.
}

Authors' contributions

This work was carried out in collaboration between all authors. Author FIO designed the study, performed the research and carried out the statistical analysis, wrote the protocol, and wrote the first draft of the manuscript. Authors KAB, JOA, HMA and DEAB supervised and managed the analysis of the study and author SAO managed the literature searches. All authors read and approved the final manuscript.

\section{Article Information}

DOI: $10.9734 / I R J P A C / 2017 / 32685$

Editor(s):

(1) Surendra Reddy Punganuru, Department of Biomedical Sciences, School of Pharmacy, Texas Tech University Health Sciences Center, Amarillo, USA.

(2) SungCheal Moon, Korea Institute of Materials Science (KIMS), Industrial Technology Support Division, Changwon, Republic of Korea. Reviewers:

(1) Nyoman Puspa Asri, W.R. Supratman University, Indonesia. (2) Quuyun Zhang, School of Chemistry and Chemical Engineering, Anshun University, China. (3) Manisara Phiriyawirut, King Mongkut's University of Technology, Thailand. Complete Peer review History: http://www.sciencedomain.org/review-history/19107

Original Research Article

Received $9^{\text {th }}$ March 2017

Accepted $4^{\text {th }}$ May 2017

Published $17^{\text {th }}$ May 2017

\begin{abstract}
This paper presents the results of x-ray diffraction of a cellulose fabric treated with oils extracted from the seed of Jatropha curcas; the oils were extracted with hexane under reflux while the fabric was purified by scouring, bleaching and mercerization to remove dirt and coloring matter in order to make it suitable for esterification. Apart from the controlled sample which was un-esterified, other samples of the same fabric were treated with different volume and concentration of the oil under the same temperature. The $\mathrm{x}$-ray diffraction analysis carried out on all samples showed that while the control sample had a sharp single peak at $24.033^{\circ}$ all the esterified samples showed broad split
\end{abstract}


peaks at angles ranging from $20.308^{\circ}$ to $22.809^{\circ}$; also while the control sample had inter-atomic (or d-spacing) of $3.702 \AA$ those of the treated sample ranged from $3.8984 \AA$ to $4.3727 \AA$, in addition to these the peak width increased from $1.5^{\circ}$ in the control sample to between $1.9^{\circ}$ to $2.8^{\circ}$ in the treated samples. Other significant results showed that the peaks intensity increased from 5489 to highest value 8313 in the sample treated with $20 \mathrm{~cm}^{3}$ of oil. Crystallinity was observed to reduce from $65 \%$ in the control to about $63 \%$ for esterified fabrics samples and lastly, crystallite size reduced from 9.9 $\mathrm{nm}$ to between $5.3 \mathrm{~nm}$ to $7.7 \mathrm{~nm}$. The observed structural modifications in treated fabric may have direct influence on the physical, mechanical properties as well as dye-ability of the treated samples. The result of water Imbibition also revealed structural modification as there was a decrease in the amount of water imbibed by esterified fabric, indicating a reduction in the number of $\mathrm{OH}$ groups in the new cellulose derivative as revealed in the $x$ - ray analysis. Hence the esterified fabric will be less susceptible to microbial attack during storage.

Keywords: Structural modification; cellulose fabric; esterification; Jatropha curcas; X-ray diffraction.

\section{INTRODUCTION}

Structurally, cellulose consists of both amorphous and crystalline regions and is the basis of all natural and man-made fibers [1-4]. While crystalline region is responsible for strength, the amorphous region is responsible for flexibility and flaws such as dimensional instability and creasing [5-6]. Hence this region is oriented to improve the intermolecular attraction in order to enhance the fibre modulus [1]. To achieve this, several researchers have applied urea and melamine formaldehyde resins on cellulose fabric [7-9]. The problems with these resins are their toxicity and environmental degradation, formation of yellow discoloration on fabric during storage, release of hydrochloric acid during ironing which causes the fabric to lose strength [10]. Moreover, these resins are costly resulting in a higher cost of the finished products.

In line with global quest for green and environmentally friendly chemistry, this research focused on the use of Jatropha curcas seed oil for a possible replacement of resin in the improvement of fabric quality. The choice of Jatropha curcas seed oil is based on its abundant availability, its under-utilization, being usually discarded as waste in this part of the world. The seed is biodegradable and has much medicinal value [11]. Mass planting of the trees and storage of the seeds will provide job opportunities for the growing population and will also serve as protection to the environment.

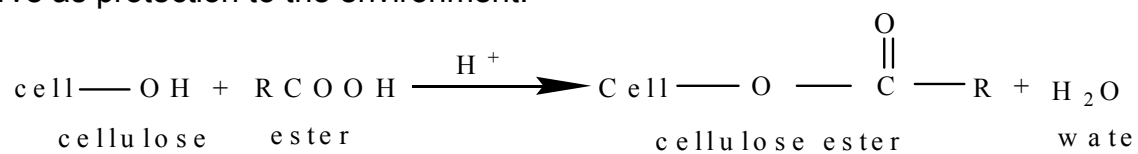

Jatropha curcas is an oil seed-yielding plant belonging to the family Euphorbiacaea, having numerous common names depending on the country where it is found. The common names are physic nut, Barbados nut, or purging nut [12]. In Nigeria, it is known by various local names as Binidazugu, Butuje, Lapalapa, Ologbo [13].It is a highly adaptable plant that can tolerate severe head and different soil types. It thrives in warmer weather but is susceptible to freeze damage even though it can tolerate a high frost of relatively short duration [14].

Jatropha curcas is used by farmers as a fence to keep grazing animals off their field because the smell and taste of the plant repel grazing animals [15]. The plant guards against erosion, keeping rich top soil from being blown away by the harsh Sahel winds. It can be planted beside other crops, without substantially reducing the yield of the field which can be a source of the extra earnings for farmers [16-17]. Over the years, so much research is ongoing trying to produce biodiesel from Jatropha curcas seed oil. However, there has been no research focus on application to textile finishing.

In this research, the oil extracted from Jatropha curcas was used for esterifying cellulosic fabric (cotton) using acid catalyst in order to modify the properties of the fabric. Equation (1) represents the reaction between the acids in the oil and hydroxyl in cellulose to form cellulose ester.

Where, $\mathrm{R}$ is the triglyceride chain. 
This paper presents the results of $\mathrm{x}$-ray diffraction obtained from reaction between $\mathrm{OH}$ of cellulose and $\mathrm{COOH}$ of the fatty acid in the oil via esterification. A cellulose mono-ester with modified structural property was obtained.

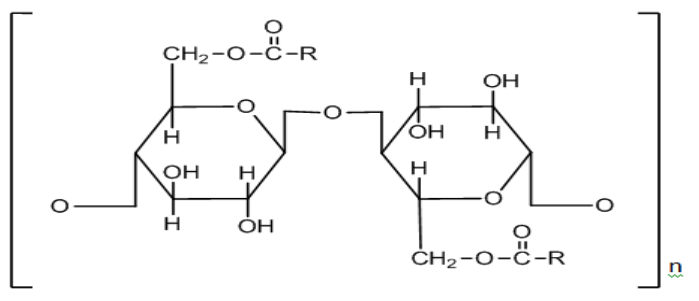

Fig. 1. Structure of cellulose monoester

\section{MATERIALS AND METHODS}

\subsection{Materials}

Jatropha curcas fruits, $100 \%$ cotton fabric, oven, Soxhlet apparatus, analytical weighing balance, beakers, heating mantle, reflux apparatus, stop clock, glass rod, water bath, syringe, piston and mortar, scissors, ruler, Bruker D8 Advance $\mathrm{x}$ ray machine, thermometer, filter paper, distilled water, Bunsen burner, forceps, chemicals of commercial grade and high purity supplied by $\mathrm{BDH}$ include; sodium sulphate, sulphuric acid, sodium hydroxide, sodium silicate, magnesium sulphate, hydrogen peroxide, acetic acid, methanol, hexane, sodium carbonate.

\subsection{Method}

\subsubsection{Extraction of oil}

Extraction and characterization of the oil was carried as described by Pearson [18]. The fruits were decoated, soaked in water for about 6 hours to dissolve the sticky pulp then sun dried. The seeds were removed from the hard shells through cracking, and kernels obtained were air dried then ground to fine powder.

The powder $(50.0 \mathrm{~g})$ was placed in a preweighed thimble and then placed in the barrel of the soxhlet apparatus. $200 \mathrm{ml}$ of $\mathrm{n}$-hexane was poured into the flask and the apparatus set for extraction and allowed to run for 6 hours. Percentage yield was calculated using equation (2);

$$
\text { Yield } \%=\frac{W_{2}-W_{3}}{W_{2}-W_{1}} \times 100
$$

Where, $W_{1}$ is the weight of empty thimble, $W_{2}$ is the weight of sample and thimble and $W_{3}$ is weight of thimble and sample after drying

\subsection{Fabric Identification and Purification}

Standard methods according to BS 11 [19] and ASTM [20] were employed for fabric analysis.

\subsubsection{Fabric Identification}

Yarns were unraveled along the warp and weft directions. These were introduced separately into the Bunsen burner flame with the aid of forceps.

\subsubsection{Solubility test}

The fabric $(1 \mathrm{~g})$ was immersed into $25 \%$ concentrated solution of sodium hydroxide at room temperature and allowed to stand for 1 hour, and then warmed at $80^{\circ} \mathrm{C}$. A fresh sample of the same size was also immersed into $25 \%$ concentrated solution of sulphuric acid and allowed to stand at room temperature for an hour.

\subsection{Purification of Fabric}

\subsubsection{Scouring of grey fabric}

$10 \mathrm{~cm} \times 10 \mathrm{~cm}$ of the grey fabric was immersed in $2 \% \mathrm{NaOH}$ solution and boiled for 1 hour. It was rinsed severally in overflowing water followed by washing in detergent solution, after which it was neutralized with $5 \%$ acetic acid then rinsed with water and dried at room temperature.

\subsubsection{Bleaching of scoured fabric}

The sample was boiled for 45 minutes in a bleaching liquor containing $5 \%$ of $\mathrm{H}_{2} \mathrm{O}_{2}, 0.1 \mathrm{~g}$ $\mathrm{NaSiO}_{3}, 10 \mathrm{ml}$ of $1 \% \mathrm{NaOH}$ solution and $0.5 \mathrm{~g}$ $\mathrm{MgSO}_{4}$, then rinsed severally in tap water for 10 minutes and neutralized with $5 \%$ acetic acid and dried at room temperature.

\subsubsection{Mercerization of bleached fabric}

The bleached fabric was immersed in $20 \%$ solution of $\mathrm{NaOH}$ at $5^{\circ} \mathrm{C}$ with occasional turning with a glass rod for 20 minutes, after which it was washed in detergent solution for 10 minutes, rinsed with tap water for 5 minutes, neutralized with $5 \%$ acetic acid, rinsed with distilled water and dried at room temperature. 


\subsection{Esterification of Mercerized Fabric}

$100 \mathrm{ml}$ of methanol was mixed with $10,20,30$, 40,50 and $60 \mathrm{ml}$ of the Jatropha curcas oil respectively in round bottom flasks; $0.5 \mathrm{ml}$ of concentrated $\mathrm{H}_{2} \mathrm{SO}_{4}$ was added and refluxed for 1 hour at $60^{\circ} \mathrm{C}$. The mercerized sample was weighed and then immersed into the flask and refluxed for 3 hours at $60^{\circ} \mathrm{C}$ with occasional shaking. The fabric was removed and neutralized in $2 \%$ solution of $\mathrm{Na}_{2} \mathrm{CO}_{3}$ in order to destroy any acid residue that remained in the sample, while the residual oil was removed by immersing the fabric in a very dilute detergent solution. The sample was rinsed in distilled water and dried in the oven at $60^{\circ} \mathrm{C}$ for 20 minutes then weighed again.

\subsection{X-ray Diffraction Analysis}

The control fabric measuring $1 \mathrm{~cm} \times 0.5 \mathrm{~cm}$ was ground into fine powder. The ground sample was placed in a glass tube and this was mounted on the Bruker D8 Advance x-ray machine at the University of Kwazulu Natal, West Ville Campus 4000, Durban South Africa. The sample was positioned in the centre of the copper source monochromatic radiation $(\lambda=1.5418 \AA)$. The diffraction pattern was generated by a radiation counter and was plotted automatically. The procedure was repeated for other fabrics esterified under varying volume of the oil. The inter-atomic distance (d-spacing) was calculated according to Bragg's law in equation (3)

$$
n \lambda=2 d \sin \theta
$$

The crystallite size was obtained from the Scherrer equation with the method based on the width of the diffraction pattern.

$$
D=\frac{k \lambda}{B \cos \theta}
$$

Where, $D$ is the size of crystallite $(\mathrm{nm}), \mathrm{k}$ is the Scherrer constant (0.94), $\lambda$ is the $x$-ray wavelength, $B$ is the full-width at half-maximum of the peaks measured in $2 \theta$ angle [21].

The percentage crystallinity was calculated according to equation (5).

$$
\text { Crystallinity }(\%)=\frac{I_{C}}{\sum I_{a}+I_{c}} \times 100
$$

Where, $I_{c}$ is intensity of crystalline peak, $I_{a}$ is intensity of amorphous peak.

\subsection{Water Imbibition}

The esterified fabric using $50 \mathrm{ml}$ of oil was used as a case study for this investigation. The fabric was weighed and soaked in $250 \mathrm{~cm}^{3}$ of distilled water in a beaker for 5 minutes. It was removed and mopped with filter paper gently to remove excess water and then reweighed again immediately. This was followed by progressive drying at $80^{\circ} \mathrm{C}$ in an oven for $5,10,15,20,25$ and 30 minutes. At each of these intervals, the weight of the sample was recorded using analytical balance. The temperature of the laboratory was maintained at $25^{\circ} \mathrm{C}$ during the experiment.

$$
\begin{aligned}
& \text { Water imbibition }(\text { regain }) \%= \\
& \frac{\text { mass of water retained }}{\text { mass of dry sample }} \times 100
\end{aligned}
$$

This determination was repeated for the control fabric.

\section{RESULTS AND DISCUSSION}

\subsection{Percentage Yield of Oil}

The seed of Jatropha curcas contain a good amount of oil (47.25\%) which could be highly economical in chemical industries. The oil is light yellow in colour, odorless, tasteless and liquid at room temperature. Therefore, this plant could be fully harnessed for oil production.

\subsection{Fabric Identification}

The burning test on the fabric showed that the fibre burned rapidly with a yellow flame, giving a powdery ash residue. The solubility test showed that the material was soluble in concentrated sulphuric acid solution but insoluble in concentrated solution of sodium hydroxide. This is indication that the fabric is $100 \%$ cellulose.

\subsection{Fabric Purification}

\subsubsection{Scouring}

When oil and fat are heated in $2 \%$ solution of sodium hydroxide, they hydrolyze to glycerol and alkali salt of the fatty acid as shown in the equation below: 


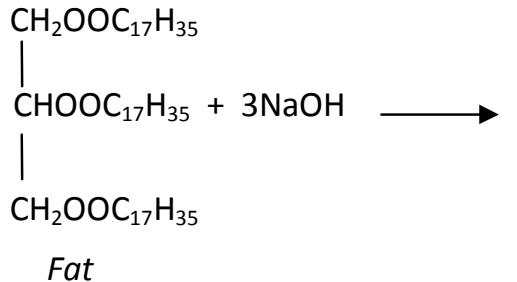

The soap produced emulsifies the unsaponifiable fats and waxes. The scoured fabric becomes more absorbent, cleaner and softer. Protein and simpler nitrogenous compounds are degraded into water soluble salts, pectin and lignin are converted to soluble salts, mechanically adhering dirt are loosened and held in suspension, the fabric is stronger and more elastic [22].

\subsubsection{Bleaching}

Hydrogen peroxide was used for the bleaching process. The whiteness of the bleached material was very significant which may be due to lose of coloring matter. Hydrogen peroxide decomposed to form per hydroxyl ion which is the active bleaching specie in the following manner;

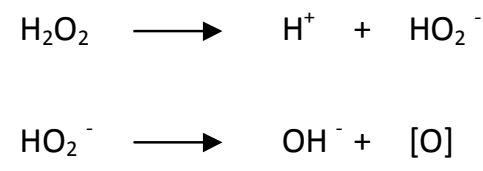

This reaction depends on the $\mathrm{pH}$ of the medium. This is because the right degree of stability is required and this can only be achieved in an alkaline medium [23]. In alkaline condition, the hydroxyl ions $\left(\mathrm{OH}^{-}\right)$produced by the per hydroxyl $\left(\mathrm{HO}_{2}^{-}\right)$, hydrolyses the hydrogen ion $\left(\mathrm{H}^{+}\right)$to produce more per hydroxyl ions [22-23].

$$
\mathrm{H}^{+}+\mathrm{OH}^{-} \longrightarrow \mathrm{H}_{2} \mathrm{O}
$$

Care must be taken in the production of per hydroxyl ion since it may decompose into hydroxyl ion and atomic oxygen. If the atomic oxygen is produced in excess, this may dissociates to form molecular oxygen.

$$
[\mathrm{O}]+[\mathrm{O}] \longrightarrow \mathrm{O}_{2}
$$

The bleaching liquor is stabilized by addition of a stabilizer such as sodium silicate. If the bleaching is made with soft water, it is necessary to add

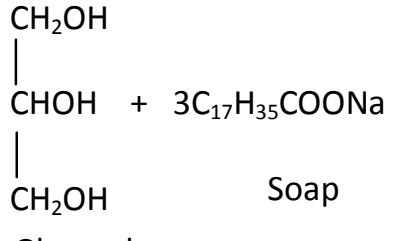

Glycerol

magnesium sulphate to provide some hardness. The magnesium sulphate reacts with sodium silicate to produce magnesium silicate and sodium sulphate [8].

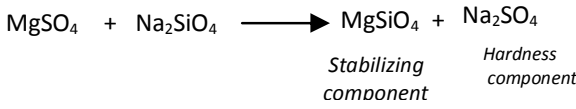

Temperature was maintained between $80^{\circ} \mathrm{C}$ to $100^{\circ} \mathrm{C}$ while $\mathrm{pH}$ was between 10 and 11 . This is because at higher temperature, oxygen may be lost rapidly while at lower temperature, the bleaching process may be too slow. Similarly, at higher $\mathrm{pH}$ hydrogen peroxide decomposes before adequate bleaching, while at lower $\mathrm{pH}$ perhydroxyl ion may not be released. This may lead to uneconomical process.

\subsubsection{Mercerization}

Mercerization involves the treatment of cotton materials with $20-22 \%$ concentration of sodium hydroxide at $0-5^{\circ} \mathrm{C}$. The resulting product is hydrated cellulose which differs from the initial cellulose by its physical properties [24]. The hydroxyl groups in the cellulose units differ in reactivity. Based on this consideration, cellulose may react with concentrated aqueous solution of alkali to form a molecular compound of cellulose with alkali $\left(\mathrm{C}_{6} \mathrm{H}_{10} \mathrm{O}_{5} \text {. } \mathrm{NaOH}\right)_{n}$ or cellulose alcoholate $\left(\mathrm{C}_{6} \mathrm{H}_{10} \mathrm{O}_{5} . \mathrm{ONa}\right)_{n}$. The formation of cellulose alcoholate takes place at the interaction of alkali with the secondary group $\mathrm{OH}$ in position 2 [24]. The mercerized fabric shrank longitudinally and swelled laterally; there was increase in luster and it was also observed that the mercerized fabric creased very badly.

\subsection{Weight of Fabric Due to Esterification}

The effect of esterification on percentage increase in weight of fabric is presented in Fig. 2, suggesting that there was increase in weight after esterification indicating that a reaction has occurred between the oil and the fabric. It showed that the highest percentage increase in 
weight $(5.79 \%)$ was achieved by esterifying the fabric with $50 \mathrm{~cm}^{3}$ of Jatropha curcas seed oil. This is an indication that this material was the densest.

\subsection{X-ray Crystallography}

The results of the $x$-ray diffraction analysis of untreated (control) and esterified fabric using Jatropha curcas seed oil with varying volume are presented in Figs. $3-9$. Generally, the results showed that the crystallographs of all esterified fabrics gave almost the same profile different from that of the control. The splitting of the peaks of esterified plots suggests that structural modification through esterification has taken place. The resulted double peaks of esterified samples are evidence of reaction between $\mathrm{OH}$ of cellulose and the -COO- of the fatty acid ester in the oils to form cellulose ester. The first peak having lower intensity account for the oxygen atom linking the cellulose while the second peak with higher intensity account for the carbonyl group of the ester. The single peak of the unesterified fabric in Fig. 3 may be due to the $\mathrm{OH}$ group in cellulose indicating absence of ester bond.

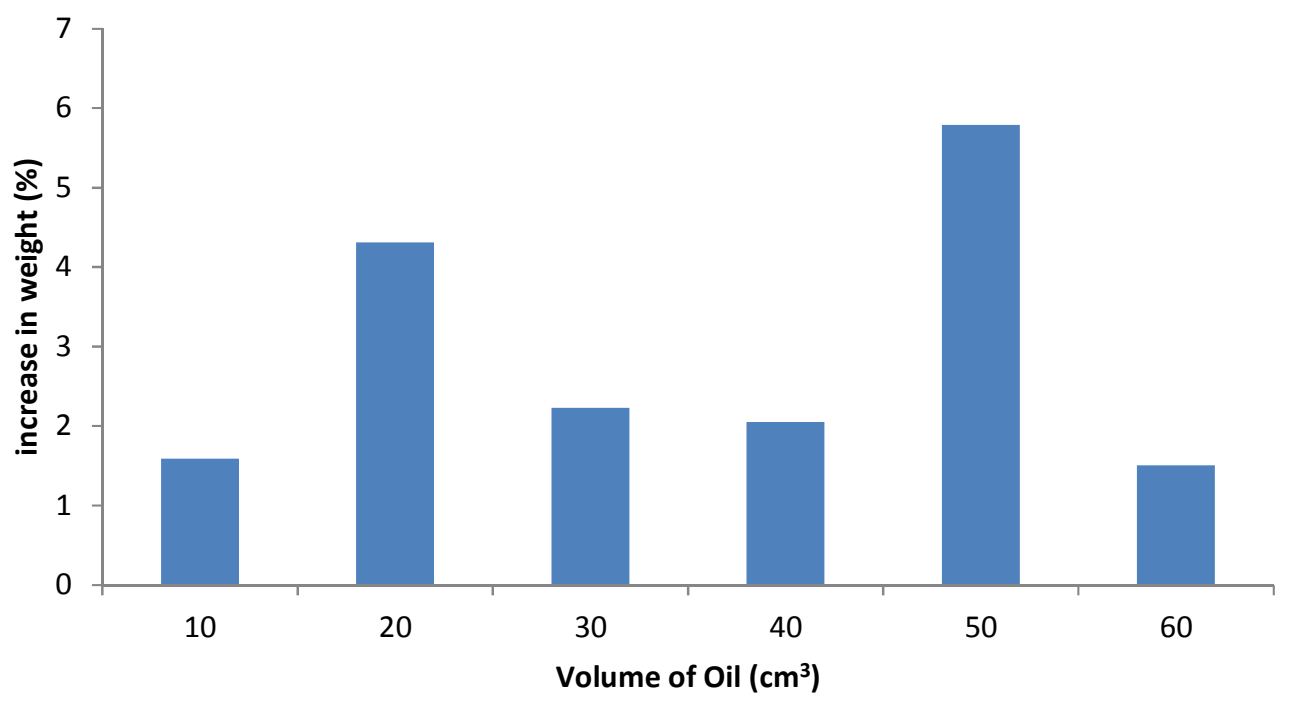

Fig. 2. Effect of esterification with varying volume of oil on fabric weight

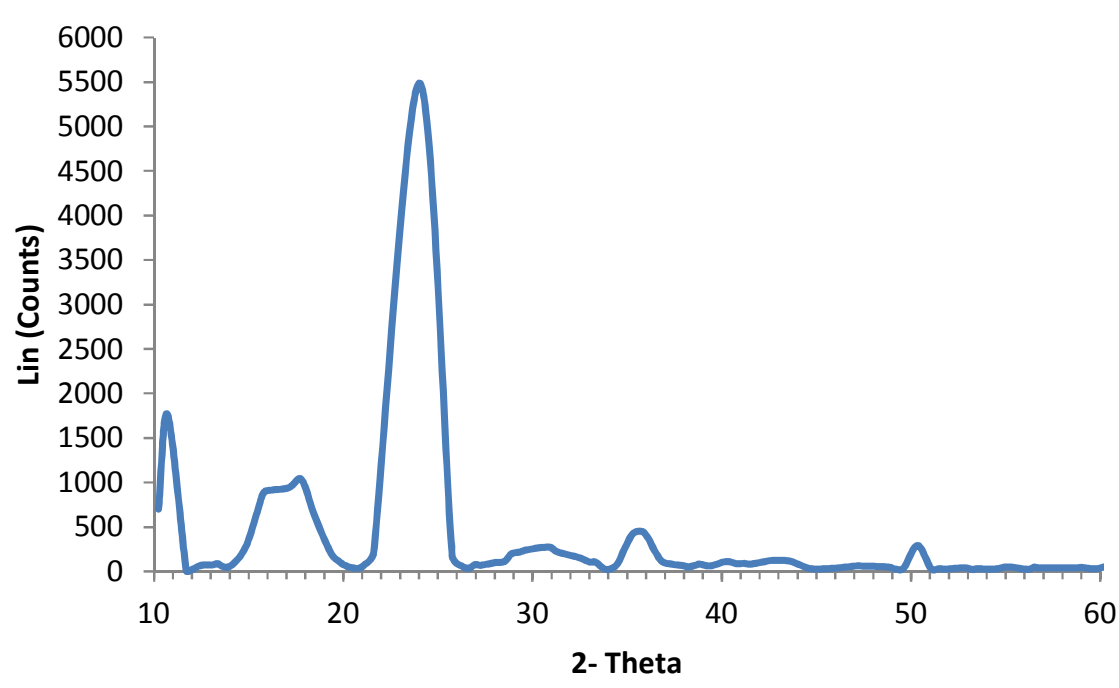

Fig. 3. X-ray crystallograph of unesterified fabric (control) 


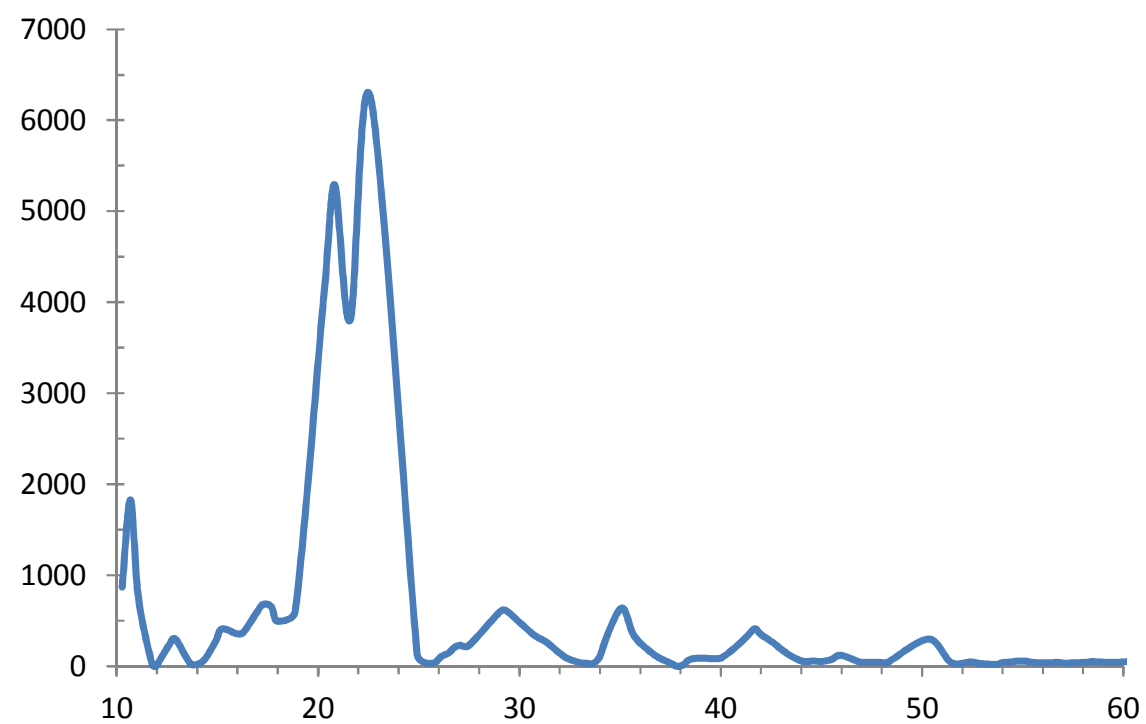

Fig. 4. X-ray crystallograph of fabric esterified with $10 \mathrm{ml}$ Jatropha curcas oil

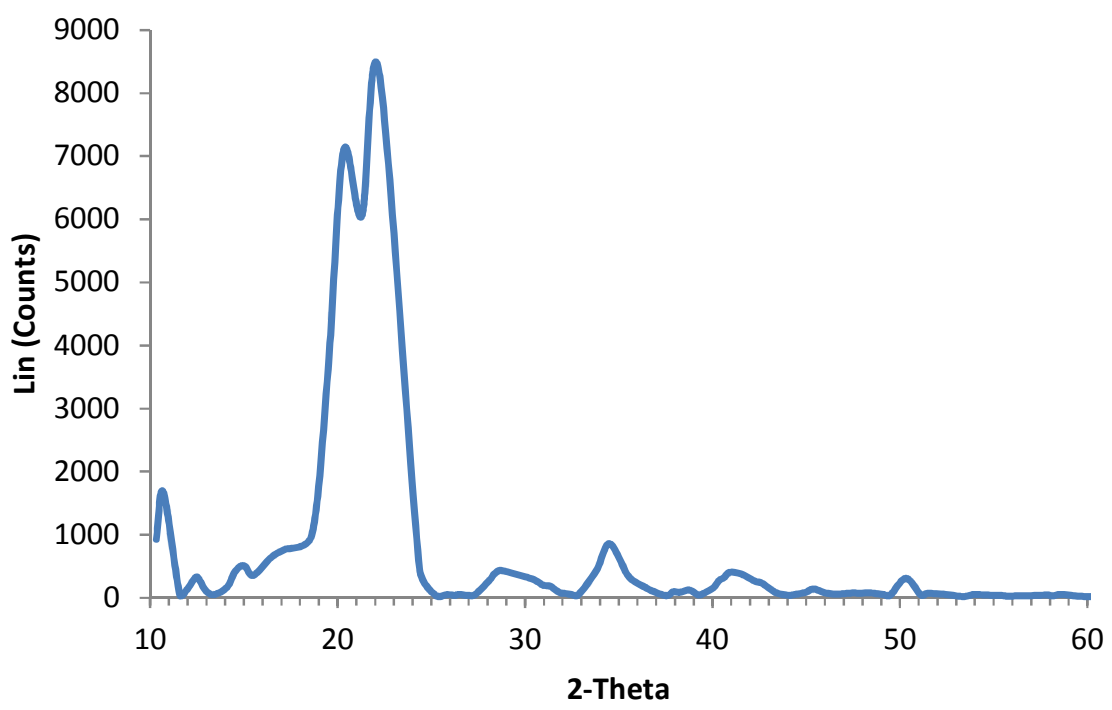

Fig. 5. X-ray crystallograph of fabric esterified with $20 \mathrm{ml}$ Jatropha curcas oil

The results of the x-ray diffraction analysis of the control and the esterified fabrics using varying volume of oil are presented in Table 1. The analysis was based on the strongest peaks in the pattern because every other peak is a characteristic of the native cellulose [25]. The functional groups were obtained from the structures of cellulose ester formed. The 2-theta angels, intensity and count were obtained from the diffraction data. Also d-spacing, peak width and crystallite size were calculated based on mathematical expressions as well as values obtained from the data.

\subsubsection{Effect of esterification on the diffractometer angle (2-theta angle)}

According to Table 1, there was a shift of diffractometer angle from $24.033^{\circ}$ (control) at $100 \%$ count to the lowest angle $\left(20.308^{\circ}\right)$ at $85.2 \%$ count for $-\mathrm{O}$ - atom after esterification with $20 \mathrm{~cm}^{3}$ of oil. The highest values of diffractometer angel $\left(22.809^{\circ}\right)$ at $96.6 \%$ count and $\left(22.617^{\circ}\right)$ at $100 \%$ count were obtained at 30 $\mathrm{cm}^{3}$ optimum volume of oil for $-\mathrm{O}$ - and $\mathrm{C}=\mathrm{O}$ respectively. These shifts in diffractometer angles may be attributed to the broadening of the 
diffractometer peaks [2] and it is indication that certainly modification has taken place in the structure of the cellulose as a result of chemical reaction with the oil.

\subsubsection{Effect of esterification on inter-atomic distance (d-spacing)}

The result in Table 1 showed that d-spacing for the control fabric was $3.7027 \AA$. After esterification there was increase in values of $d$ spacing as the volume of oil increased. The values ranged from $3.8984 \AA-4.3727 \AA$ at $99.6 \%$ count and $85.2 \%$ count respectively for O- as well as $3.9312 \AA$ to $4.0702 \AA$ at $100 \%$ count for $\mathrm{C}=\mathrm{O}$. The maximum values $(4.3727 \AA$ and $4.0702 \AA$ ) for $-\mathrm{O}$ - and $\mathrm{C}=\mathrm{O}$ respectively were obtained at $20 \mathrm{~cm}^{3}$ and $60 \mathrm{~cm}^{3}$ of oil. Increase in d-spacing for esterified samples suggests that there is modification in the structure of cellulose which may consequently lead to a decrease in the crystallinity of the esterified fabrics [26].

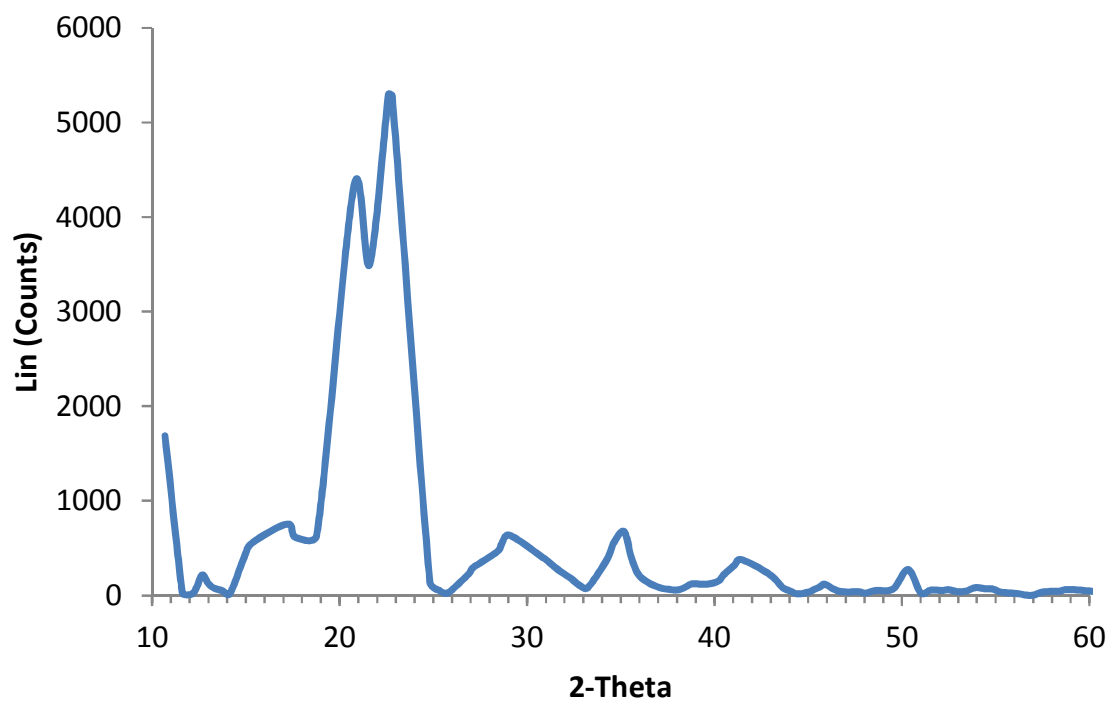

Fig. 6. X-ray crystallograph of fabric esterified with $30 \mathrm{ml}$ Jatropha curcas oil

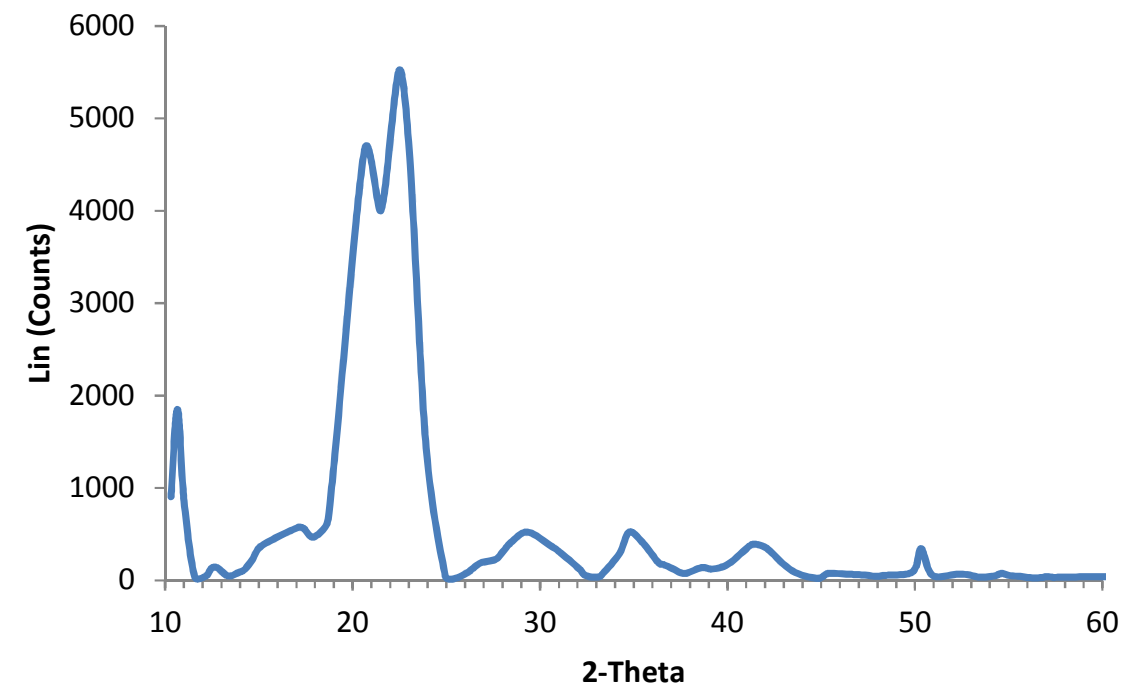

Fig. 7. X-ray crystallograph of Fabric esterified with $\mathbf{4 0} \mathrm{ml}$ Jatropha curcas oil 
Omizegba et al.; IRJPAC, 14(2): 1-13, 2017; Article no.IRJPAC.32685

Table 1. X-ray diffraction analysis of fabric esterified with varying volume of Jatropha curcas oils

\begin{tabular}{|c|c|c|c|c|c|c|c|c|c|c|c|c|c|}
\hline Properties & $10 \mathrm{~cm}^{3}$ & & $20 \mathrm{~cm}^{3}$ & & $30 \mathrm{~cm}^{3}$ & & $40 \mathrm{~cm}^{3}$ & & $50 \mathrm{~cm}^{3}$ & & $60 \mathrm{~cm}^{3}$ & & Unesterified \\
\hline Atoms & $-\mathrm{O}-$ & $C=O$ & $-\mathrm{O}-$ & $C=O$ & $-0-$ & $\mathrm{C}=\mathrm{O}$ & $-\mathrm{O}-$ & $C=O$ & $-\mathrm{O}-$ & $C=O$ & $-\mathrm{O}-$ & $C=O$ & $\mathrm{O}-\mathrm{H}$ \\
\hline $\begin{array}{l}\text { 2-theta } \\
\text { Angle }\left({ }^{\circ}\right)\end{array}$ & 20.807 & 22.626 & 20.308 & 22.224 & 22.809 & 22.617 & 20.619 & 22.480 & 20.414 & 22.299 & 21.618 & 21.836 & 24.033 \\
\hline d-spacing $(\AA)$ & 4.2685 & 3.9302 & 4.3727 & 3.9995 & 3.8984 & 3.9312 & 4.3079 & 3.9554 & 4.3505 & 3.9860 & 4.1104 & 4.0702 & 3.7027 \\
\hline Intensity & 5292 & 6220 & 7079 & 8313 & 5280 & 5300 & 4641 & 5519 & 4474 & 5084 & 6064 & 6225 & 5489 \\
\hline Count (\%) & 85.1 & 100.00 & 85.2 & 100.0 & 99.6 & 100.0 & 84.1 & 100.0 & 80.8 & 91.8 & 97.4 & 100.0 & 100.0 \\
\hline $\begin{array}{l}\text { Peak } \\
\text { Width }\left({ }^{\circ}\right)\end{array}$ & 2.0 & 2.1 & 2.3 & 2.4 & 2.8 & 2.1 & 2.0 & 2.1 & 1.9 & 2.0 & 2.2 & 2.2 & 1.5 \\
\hline $\begin{array}{l}\text { Crystallite } \\
\text { Size }(\mathrm{nm})\end{array}$ & 7.4 & 7.0 & 6.4 & 6.2 & 5.3 & 7.0 & 7.4 & 7.0 & 7.7 & 7.4 & 6.7 & 6.7 & 9.9 \\
\hline
\end{tabular}




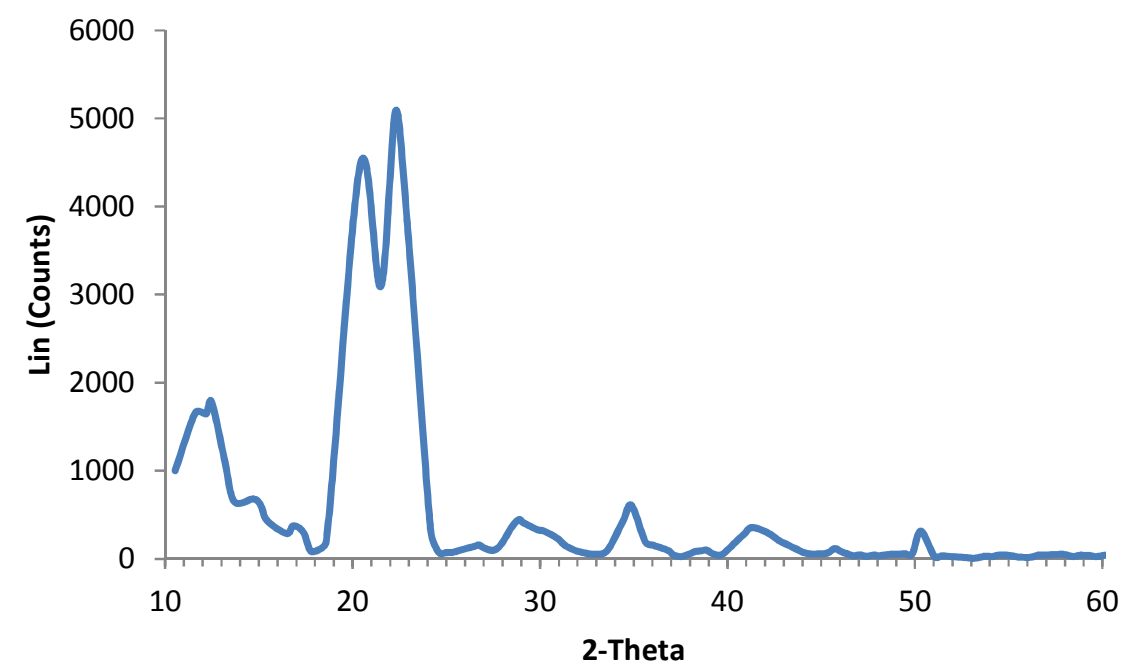

Fig. 8. X-ray crystallograph of fabric esterified with $\mathbf{5 0 ~} \mathrm{ml}$ Jatropha curcas oil

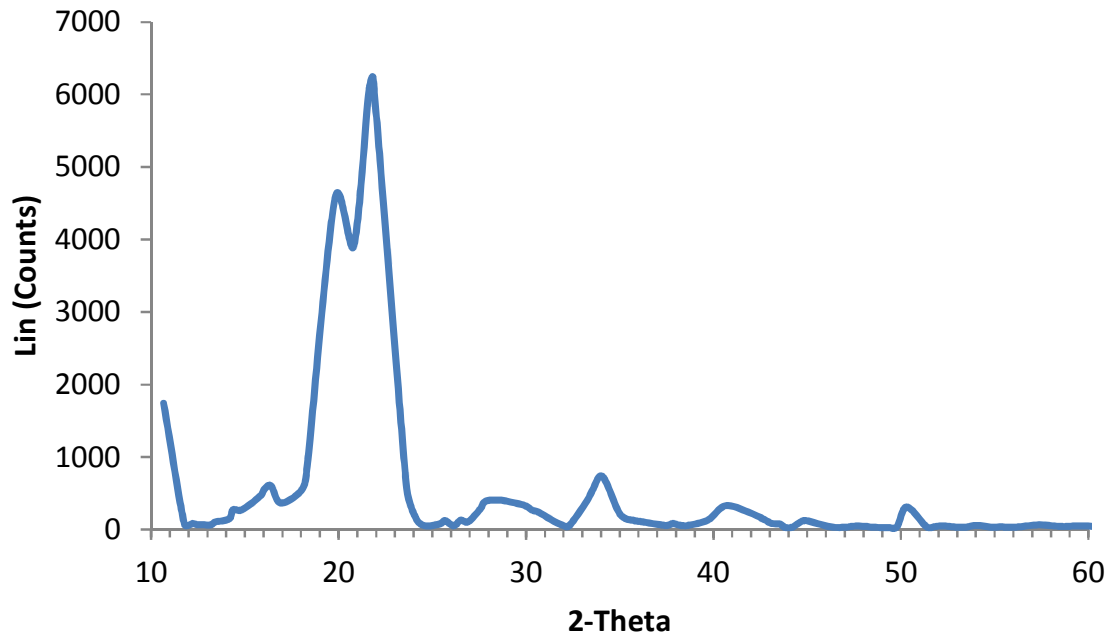

Fig. 9. X-ray Crystallograph of Fabric Esterified with $60 \mathrm{ml}$ Jatropha curcas oil

\subsubsection{Effect of esterification on peaks intensity}

The control fabric gave intensity of 5489 at $100 \%$ count. After esterification peaks intensity increased as the volume of oil increased except for fabric esterified with $10 \mathrm{~cm}^{3}$ of oil. However, the maximum values (7079 and 8313 ) of intensity for $-\mathrm{O}$ - and $\mathrm{C}=\mathrm{O}$ at $85.3 \%$ and $100 \%$ count respectively were obtained with $20 \mathrm{~cm}^{3}$ optimum volume of oil.

\subsubsection{Effect of esterification on peaks width}

The peak widths were obtained from the crystallographs shown in Figs. 3-9 by measuring the full- width at half maximum in 2-theta angle for each peak. The smallest value $\left(1.5^{\circ}\right)$ was obtained for the control fabric. This implies that this fabric may be more crystalline than the esterified fabrics.

Esterification led to increase in peaks width which ranged from $1.9^{\circ}-2.8^{\circ}$ as the volume of oils increased. The widest peak $\left(2.8^{\circ}\right)$ and the narrowest $\left(1.9^{\circ}\right)$ were observed from using 30 $\mathrm{cm}^{3}$ and $50 \mathrm{~cm}^{3}$ of oil respectively, with $30 \mathrm{~cm}^{3}$ as the optimum volume of oil. The observed increase in peak width may be due to the presence of ester bond. It may also be as a result of increase in d-spacing and diffractometer angle similar to that reported by Ericka et al. [25]. This may consequently lead to decrease in crystallinity of the esterified fabrics. 


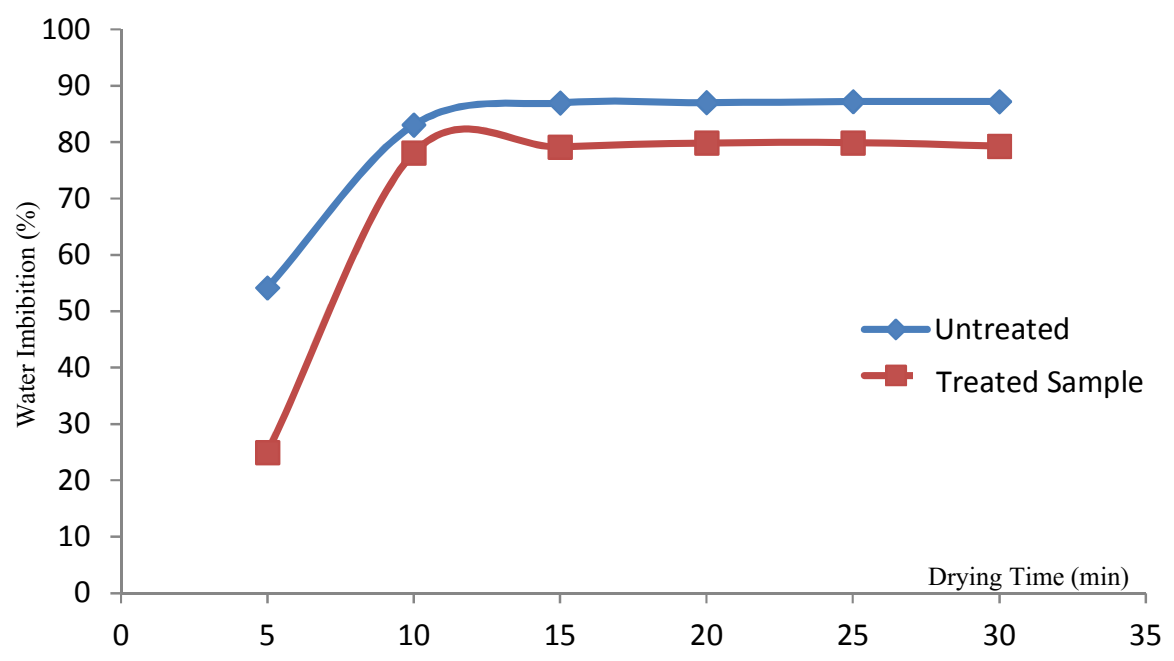

Fig. 10. Effect of Esterification on Water Imbibition

\subsubsection{Effects of esterification on crystallite size}

The crystallite size of control fabric was $9.9 \mathrm{~nm}$. Clearly, there was a decrease in crystallite size after esterification which ranged from $5.3 \mathrm{~nm}$ (lowest) for -O- at $30 \mathrm{~cm}^{3}$ of oil and $7.7 \mathrm{~nm}$ (highest) for -O- at $50 \mathrm{~cm}^{3}$ optimum volume of oil. The observed decrease in crystallite sizes may be attributed to the presence of short chain alkyl groups of the ester. The presence of small crystallites in polymer may lead to reduction in alignment of polymer chains. This molecular irregularity therefore, is an indication that crystallinity is reduced [2].

\subsubsection{Effect of esterification on percentage crystallinity}

Crystallinity determines the strength [27] and other very important mechanical properties such as the ability to recover from deformation [1]. It is also a determinant of the end use of any polymer product.

With respect to Table 2, the percentage crystallinity of the control cellulose is $65 \%$. After esterification, percentage crystallinity reduced to $63 \%$ at $20 \mathrm{~cm}^{3}$ optimum volume of oil. This decrease may be attributed to factors like increase in d-spacing, decrease in crystallite size and broadening of peak width [2, 25, 28]. Other factors include the presence of bulky ester side groups $\left(\mathrm{OCOCH}_{3}\right)$ and loss of alignment of the polymer chain [29]. The extent of esterification according to the $x$-ray results showed that a cellulose mono-ester was produced with the ester group attached to carbon six on the cellulose chain. The decrease in crystallinity led to a decrease in porosity as observed in Fig. 10, suggesting that a bulky ester group co-exist with $\mathrm{OH}$ in the cellulose chain.

Table 2. Percentage crystallinity

\begin{tabular}{ll}
\hline Volume of Oil $\left(\mathbf{c m}^{3}\right)$ & $\begin{array}{l}\text { Jatropha oil esterified } \\
\text { fabric crystallinity } \%\end{array}$ \\
\hline 0 & 65 \\
10 & 63 \\
20 & 63 \\
30 & 63 \\
40 & 63 \\
50 & 63 \\
60 & 63 \\
\hline \multicolumn{2}{c}{$0^{2} \mathrm{~cm}^{3}$ is for unesterified sample }
\end{tabular}

\subsubsection{Effect of esterification on water imbibition}

The uptake or absorption of water by a substance without forming a solution is called Imbibition. It is the property of many biological substances including cellulose, starch and protein. The prerequisite for water absorption by any substance is the affinity between the absorbent and water. Proteins have very high imbibing capacity, then starch less and cellulose least [30]. The water Imbibition of grey and Jatropha curcas esterified fabric is as shown in Fig. 10, where it can be observed that the grey 
fabric recorded the highest water retention capacity at 20 min drying period, suggesting that this sample has maximum hydrophilicity. In contrast, the esterified fabric gave a lower retention capacity. These findings further supported the x-ray diffraction results which showed that 1 out of $3-\mathrm{OH}$ groups in the cellulose fabric has been replaced by O-COester linkage to form a cellulose monoester. Hence, the esterified fabric will have a better resistance to microbial attack during storage.

\section{CONCLUSION}

Cellulose fabric was esterified by varying the volume of Jatropha curcas seed oil. The x-ray results showed that there was a chemical reaction that took place between the $\mathrm{OH}$ of cellulose and -COO- of the fatty acid ester in the oil of Jatropha curcas which has led to structural modification and formation of cellulose monoester. This modification resulted in slight decrease in percentage crystallinity, increase in d-spacing, peak width, fabric weight and reduction in crystallite size and reduction in water retention. Hence this fabric will have better resistance to mildew and other micro organisms during storage. Based on these findings, Jatropha curcas oil contains a good amount of oil which could be fully harnessed. It is recommended for easy-care finish in the textile industry because the oil is non-toxic, biodegradable and locally available than amino resins.

\section{COMPETING INTERESTS}

Authors have declared that no competing interests exist.

\section{REFERENCES}

1. Morton WW, Hearle JWS. Physical properties of Textile fibers. Textile institute: Heiemann, ( $2^{\text {nd }}$ ed.). London. 1975;376438.

2. Billmeryer FW. Textbook of polymer science. John Wiley and Sons Inc. ( $3^{\text {rd }}$ ed.). New York. 1984;236-294.

3. Pandey JK, Takagi H, Nakagaito AN, Kim $\mathrm{H}$. Handbook of polymer nanocomposites. Processing, Performance and Application. Springer Heidelberg New York, Dordrecht London. 2015;28.

4. Harder F. Fashion for Profit: A professional's complete Guide to Designing. Harder Publications. Rolling
Hills Estate C.A., USA. (6 th $^{\text {ed.). }}$ 2004;110114.

5. Klemn D, Briggitle $H$, Hans-Peter $F$. Andreas B. Cellulose: Fascinating biopolymer and sustainable raw material. chemical information. A Journal of the Gesellchaft Deutscher Chemiker. John Wiley \& Sons, Ltd. 2005;36:36.

6. Carraher CE. Introduction to polymer chemistry $\left(2^{\text {nd }}\right.$ ed. $)$. CRC Taylor \& Francis Groups. London. 2010;25.

7. Attah FI. Resination and crease recovery of polyester and cellulosic fabric. Unpublished B. Tech Thesis. Abubakar Tafawa Balewa University, Bauchi; 1995.

8. Omizegba FI. Studies of Dye-Resin-Fibre Network. Unpublished Master's Thesis. Abubakar Tafawa Balewa University, Bauchi, Nigeria; 2004.

9. Ezeribe Al, Chukwu CJ, Obasi NA, Christian GO, Ibiam UA. Effects of catalyst concentration on the rheological properties of melamine formaldehyde resinated cotton fabric. Asian Journal of Textile. 2012; I(2):26-31.

10. Timar-Balazsy A, Eastop D. Chemical principles of textile conservation. Routlege 2 Park Square, Milton Park, Abingdon, Oxon. New York. USA. 2011;106.

11. Acheten MJ, Varco L, Franken YJ, Mathijs E, Singh VP, Aerts R, Muys B. Jatropha Bio-Diesel production and use. Biomass Bioenergy. 2008;32:1063-1084.

12. Institute of Food and Agricultural Sciences. Food and Agricultural Sciences. Journal of Agriculture and Biological Sciences University of Florida. Gainesville, Fla, 2011;5(4):338-343.

13. Kakute Ltd. Collection of seeds, oil and soap making. 2003; Accessed May 7, 2013.

Available:http://www.drugsalectinspeasandbeans,html

14. Moore K, Greenhut S, Vendrame W. Green house production of Jatropha, a potential Biofuel Crop. Hort Technology. 2011;21:193-197.

15. Conway G. One billion hungry; can we feed the world. Comstock Publishing Associates, A division of Cornell University Press. London. 2012;326.

16. Openshaw K. A review of Jatropha curcas L: An oil plant of unfulfilled promise Biomass Bioenergy. 2000;19:1-15.

17. Nahar K. Sweet sorghum: An alternative feedstock for Bioethanol. Journal Environ. Sci. Technol. 2011;4:498-503. 
18. Pearson D. Fats and oils composition and analysis of foods. Concord Publishers; London. 1994;70-84.

19. British Standard Handbook 11. Methods of Test for Textiles. British Standard Institution. 1974;171-183:578.

20. American Society for Testing Materials ASTM. Standard Test Method for Tear and Resistance of Woven Fabrics by Falling Pendulum (Elendrof) Apparatus (9.01). American Society for Testing and Materials, Philadelphia, PA USA. 1994;3874.

21. Oh SY, Yoo D, Shin Kim HC, Kim HY, Chung YS, Park WH, Yonk JH. Crystallite structure analysis of cellulose treated with Sodium Hydroxide and Carbon dioxide by means of x-ray diffraction and FTIR Spectroscopy. Science Direct. 2005;340:2376-2391. Accessed September 8, 2016.

Available:http://www.sciencedirect.com

22. Ajayi JO, Bello KA. Colour and textile chemistry. ( $1^{\text {st }}$ ed.). 2005;5-11.

23. Trotman ER. Dyeing and chemical technology of textile fibers. Charles Griffin Co. Ltd. (4 ${ }^{\text {th }}$ ed.) London. 1970;59-81,596.

24. Sadov $F$, Korchagin $M$, Matelsky $A$. Chemical technology of fibrous material. MIR Publishers, 1973;14:512-642.
25. Ericka N, Shaathkuwar KM, Shelby FT, James WR. X-ray diffraction of cotton treated with neutralized vegetable oilbased macromolecular cross linkers. Journal of Engineered Fibers and Fabrics. 2010;5(1):10-20.

26. Yuping W, Cheng F, Guili H. Synthesis and properties of fatty acid esters of cellulose. Journal of Scientific and Industrial Research. 2007;66:1019-1024.

27. Omizegba FI, Boryo DEA, Chindo IY, Oni $O$. Effect of degree of substitution and viscosity of urea formaldehyde resin on creasing property of Cellulosic Fabric. Journal of Chemical Society of Nigeria. 2015;40(2):106 -109.

28. Tripp VW, Conrad CM. Instrumental analysis of cotton cellulose and modified Cotton Cellulose, O'connor; R. T. Edition McCell Dekker Inc. New York. 1972;339.

29. Bello MA. Polymers the chemistry and technology of modern materials. Concept Publications Ltd. Lagos. 2001;33-46:225226.

30. Kumar S. Imbibition; 2016.

Retrieved on December 21, 2016. Available:www.biologydiscussion.com

(c) 2017 Omizegba et al.; This is an Open Access article distributed under the terms of the Creative Commons Attribution License (http://creativecommons.org/licenses/by/4.0), which permits unrestricted use, distribution, and reproduction in any medium, provided the original work is properly cited.

Peer-review history:

The peer review history for this paper can be accessed here: http://sciencedomain.org/review-history/19107 